\title{
O PAPEL DOS ESQUEMAS NA MEMÓRIA DE IDOSAS SAUDÁVEIS
}

\author{
Claudimara Chisté Santos \\ Antonio Carlos Ortega
}

\begin{abstract}
RESUMO. A memória é tradicionalmente estudada pela psicologia cognitiva e pela neurociência. A presente pesquisa se baseia em uma obra de Piaget dedicada ao estudo desse fenômeno com base em paradigmas construtivistas e replica um de seus experimentos, fazendo uma adaptação dos níveis de análise. O objetivo que orientou esse estudo foi identificar o papel dos esquemas em um experimento de memória no sentido amplo, com base na teoria de Piaget. As seis participantes que contribuíram com o estudo estavam, na época da pesquisa, com idades entre 61 e 67 anos e tinham, no mínimo, o Ensino Médio. Os resultados indicam que: (1) a adaptação dos níveis de análise atendeu à classificação da memória no experimento; (2) foi possível identificar, por meio do método clínico, a participação dos esquemas construídos ao longo da vida como recurso para recuperação da informação, o que pode contribuir para futuros estudos sobre intervenção na memória de idosos.
\end{abstract}

Palavras-chave: Memória; envelhecimento; construtivismo.

\section{THE ROLE OF SCHEMES IN HEALTHY ELDERLY WOMEN'S MEMORY}

\begin{abstract}
The memory is typically studied by cognitive psychology and neuroscience. This research builds on a book by Piaget which is dedicated to the study of this phenomenon based on constructivist paradigms and it replicates one of his experiments, making an adaptation of the levels of analysis. The purpose that guided this study was to identify the role of schemas in a memory experiment in a broad sense, based on Piaget's theory. The six study participants who contributed at the time of the survey were aged between 61 and 67 years and had at least high school. (1) the adjustment of the levels of analysis met the classification of memory in the experiment, (2) it was possible to identify through the clinical method, the contribution of schemes constructed throughout life as a resource for information retrieval, which may contribute to future studies about intervention on the memory of the elderly.
\end{abstract}

Key words: Memory; aging; constructivism.

\section{EL PAPEL DE LOS ESQUEMAS EN LA MEMORIA DE LOS ANCIANOS SANOS}

RESUMEN. Esta investigación se basa en la obra de Piaget dedicado a estudiar este fenómeno sobre la base de paradigmas constructivistas y una réplica de sus experimentos, haciendo una adaptación de niveles de análisis. El objetivo rector de este estudio fue identificar el papel de los esquemas en la memoria de un experimento en el sentido más amplio, basado en la teoría de Piaget. Los seis participantes que han contribuido al estudio en el momento de la encuesta de edades comprendidas entre los 61 y 67 y tuvo al menos la enseñanza secundaria. Los resultados indican que: (1) la modificación de los niveles de análisis se reunió la clasificación de la memoria en el experimento, (2) se identificó a través del método clínico, la contribución de los sistemas construidos a lo largo de la vida como un recurso para la recuperación de la información, que pueden contribuir a los estudios de intervención futura en la memoria de los ancianos.

Palabras-clave: Memoria; envejecimiento; constructivismo.

A memória, tradicionalmente, é pesquisada por meio dos constructos da psicologia cognitiva e da neurociência, no entanto Piaget e Inhelder (1979) publicaram um livro dedicado exclusivamente ao estudo desse fenômeno. O presente artigo traz os resultados da adaptação de um dos experimentos relatados na obra citada, com seis mulheres acima de 60 anos, sendo os dados também analisados com base no entendimento construtivista piagetiano do desenvolvimento humano.

Psicóloga, doutora pelo Programa de Pós-Graduação em Psicologia da Universidade Federal do Espírito Santo. Docente da Faculdade Brasileira - UNIVIX.

\# Doutor. Professor colaborador do Programa de Pós-Graduação em Psicologia da Universidade Federal do Espírito Santo. 
Inicialmente será relatada uma breve revisão de literatura de estudos sobre a memória, e em seguida será descrita uma definição do termo à luz da teoria piagetiana.

O tema memória é vasto e abordado por diversas áreas do conhecimento, por isso é necessária uma atenção especial à definição desse objeto de estudo. Nas bases de dados Scielo (Brasil), Pepsic, PsicInfo e Lilacs não foram encontrados estudos sobre memória com o referencial piagetiano. Por essa razão, a revisão de literatura teve que ser ampliada e passou a ter como objetivos identificar: (1) o tratamento recebido pelo tema na literatura, isto é, se a memória tem sido ela própria, ou tratada como um objeto de estudo ou utilizada como um instrumento de medida, um parâmetro para estudo de outros fenômenos; (2) os tipos de memória que foram mais frequentes nas pesquisas encontradas no período de 2000 a 2010. A base de dados escolhida para a revisão nacional foi a Scielo, e para a revisão internacional foi a revista Memory (ISSN 1464-0686). Revistas como Gerontology e Age e Ageing também foram objetos de investigação, mas não trouxeram artigos em número suficiente para uma análise quantitativa.

$\mathrm{Na}$ base de dados Scielo, o primeiro procedimento foi procurar artigos com um único descritor - memória - em estudos publicados entre os anos de 2000 e 2010. A análise se restringiu ao título e ao resumo. Ao todo, foram encontrados 679 artigos. Desses, 489 trabalhos não foram analisados porque seus temas fugiam ao escopo desse estudo, uma vez que se referiam a áreas como equação matemática, mecatrônica, memória imunológica, memória cultural, fisiologia, anatomia, medicamentos para memória, história e psicanálise. Tais dados só reforçam a hipótese de que o tema memória pode ser abordado com os mais variados conceitos e metodologias.

Restaram, então, 190 artigos, que foram analisados por meio de seus títulos e resumos. Nos artigos em que os resumos não foram suficientes para apresentar o tipo de memória investigado ou mencionado, o texto completo era objeto de análise.

$\mathrm{Na}$ análise foram formuladas oito categorias: (1) Memória e co-morbidades (acidente vascularcerebral, parkinson, alzheimer, obesidade, esclerose), com 75 artigos, correspondendo a 39,5\% do total, dos quais 25 não mencionaram o tipo de memória ou a definição de memória utilizada no resumo; (2) Avaliação da memória (criação, avaliação ou adaptação de instrumentos para aferir diferentes tipos de memória), com 37 artigos (19,5\%); (3) Memória em crianças (inclui transtornos de aprendizagem e autismo), com 34 artigos $(17,8 \%)$, dos quais dois não mencionaram o tipo de memória estudada; (4) Memória em idosos (o envelhecimento era o tema da pesquisa ou os participantes eram todos idosos), com 23 artigos encontrados $(12,1 \%)$, três dos quais não mencionaram o tipo de memória; (5) Memória como objeto de estudo ou tema central do artigo, com sete artigos (3,7\%); (6) Falsas memórias e (7) Memória e transtorno de déficit de atenção, ambas com seis artigos (3,2\%. cada); (8) Comparação de memória em jovens e em idosos, com 2 artigos (1\%).

Um ponto que se coloca como relevante na análise dos dados da revisão da literatura nacional é o fato de que a maior parte $(39,5 \%)$ dos artigos da base de dados Scielo pesquisados busca compreender como a memória se comporta em doenças específicas, sendo usada como um marcador, um parâmetro para identificar a saúde do paciente.

$\mathrm{Na}$ segunda $(19,5 \%)$ e na terceira $(17,8 \%)$ categorias observa-se uma preocupação com a aferição da memória e com a memória em crianças, respectivamente. A hipótese inicial nessa revisão de literatura, de que o tema envelhecimento seria um dos mais associados à memória, não se confirmou, ficando em quinto lugar em frequência de artigos (12,1\%), além dos dois artigos que comparam memória de jovens e idosos (1\%). Tal situação se deve ao fato de que morbidades como alzheimer, doença de parkinson e esclerose acometem mais idosos e, para esses casos, foi formulada outra categoria. Pode-se concluir, então, que a memória no idoso saudável é menos pesquisada do que a memória em idosos com doenças crônicas e degenerativas.

Em relação ao segundo objetivo da revisão, que foi identificar qual o tipo de memória era mais frequente nas pesquisas, foi possível observar que $15,8 \%$ mencionavam o termo "memória" sem definila, seja na revisão de literatura, seja na utilização como uma variável.

Na revisão internacional, por sua vez, foi feito um recorte com um período menor, abarcando os anos de 2009 a 2010, uma vez que a revista Memory é especializada e todos os artigos publicados continham material para análise, perfazendo o total de 144 artigos.

Houve uma diferença no procedimento de coleta dos dados nessa revista. A maioria dos artigos respondeu aos objetivos da revisão apenas com a análise do título, especificando o tipo de memória ou até mesmo transformando o objetivo em título. Quando isso não aconteceu, o resumo foi suficiente para responder às indagações. Em nenhum deles foi necessário acessar o artigo completo, e todos especificaram o tipo de memória de que tratavam. As 
categorias formuladas para essa análise foram: (1) Avaliação da memória (criação, avaliação ou adaptação de instrumentos para aferir diferentes tipos de memória), com 35 artigos (24,3\%); (2) Memória autobiográfica, com 34 artigos (23,5\%); (3) Aspectos afetivos/emocionais interferindo na memória e (4) Memória episódica, ambas com 10 artigos $(6,9 \%$ cada); (4) Memória social/cultural e (5) Memória de trabalho, ambas com sete artigos (4,9\% cada); (6) Falsas memórias (4,2\%); (7) Memória de curto prazo, (8) Metamemória/Metacognição e (9) Memória prospectiva e/ou retrospectiva, estas três últimas categorias com quatro artigos (2,8\% cada); (10) Temas com representatividade menor (de 1 a 3 artigos em cada uma delas), com 23 artigos (16\%).

Como se pode observar, a verificação e procedimentos de medidas para memória também é uma preocupação dos artigos dessa revista (24,3\%) tanto quanto daqueles das revistas brasileiras pesquisadas. Talvez por causa da linha editorial da revista, não foi tão comum encontrar artigos em que a memória fosse um indicador de saúde em morbidades específicas, e os dois únicos artigos encontrados foram computados na categoria "Temas com representatividade menor".

A memória autobiográfica é tema recorrente $(23,5 \%)$ na revisão internacional, e nos artigos brasileiros tal fenômeno recebe, por vezes, a denominação de "histórias de vida". Com o descritor "memória autobiográfica" aparecem no Scielo cinco artigos que foram classificados em outras categorias (três sobre comorbidades; um sobre fisiologia, que não foi classificado, e um que não trazia nenhuma referência à memória autobiográfica). Pesquisar esse tipo de memória parece ser uma tendência internacional que não está sendo seguida no Brasil, ao menos com essa nomenclatura, visto que os artigos nacionais mais recentes sobre memória autobiográfica datam de 2007.

Observa-se ainda uma pulverização de temas de pesquisa na revista internacional, ou seja, apesar de os autores definirem com precisão o tipo de memória que investigaram, há uma diversidade de métodos, teorias e conceitos.

Considerando os artigos analisados, tanto nas revistas brasileiras quanto na internacional, é possível identificar que a memória, na maioria dos casos, é investigada em relação à capacidade de reter e recuperar informações. O que a maioria tem em comum é o fato de pesquisar o resultado final da ação, quantificar os índices de acerto e descrever situações que favorecem ou não melhores resultados. Este, aliás, é o termo que sintetizaria a maioria dos artigos pesquisados: resultado. Apesar de não ser este o foco na presente pesquisa, não se trata de forma alguma de criticar os paradigmas adotados nas pesquisas encontradas, até mesmo porque no presente estudo também se pretendeu classificar as respostas dos participantes em níveis. Esse comentário se deve ao fato de que Piaget, ao propor o estudo da memória, o faz em termos de outros paradigmas, e tal ponto precisa ser esclarecido para definir objetivamente o que se entende por memória nesse artigo.

\section{O PAPEL DA MEMÓRIA NA TEORIA PIAGETIANA}

Para Piaget e Inhelder (1979, a memória não pode ser vista como

(...) uma tomada de posse de elementos imediatos e presentes (hic et nunc), simplesmente como uma apreensão mais ou menos direta daquilo que já foi adquirido ou vivido no passado. A forma mais elementar de memória, que é o reconhecimento, poderia (...) parecer dividir-se somente em dois elementos: uma percepção, de um lado, e uma lembrança análoga, de outro, sendo que esta lembrança se resume à simples conservação de algum componente que tenha pertencido àquela percepção anterior (p. 1).

Segundo os autores, a própria percepção pode admitir planos diferentes de estruturação, comporta inclusive a identificação ou assimilação. Há memórias que correspondem ao estádio sensório-motor, portanto são regidas por leis da boa forma, como apregoa a Gestalt. Também há memórias apoiadas em esquemas perceptivos e próprios do pré-operatório ou operatório. A memória atualiza os esquemas construídos no passado, ao invés de necessariamente recuperar dados isolados, sem relação entre si.

Avança-se na discussão sobre memória, Piaget e Inhelder (1979) discutem a dificuldade de se diferenciar uma memória propriamente dita - ou seja, a evocação de um dado anterior - da memória evolutiva, inata, como é o caso de uma memória perceptiva para a Gestalt. Outro questionamento feito pelos autores é a dúvida sobre a relação entre os esquemas perceptivos, esquemas de hábitos, esquemas conceituais, etc., com o dado evocado. Em outras palavras, como isolar, no desenvolvimento cognitivo, as influências hereditárias do que é, de fato, memória? Como definir memória? Os autores falam de três conceituações sobre memória, as quais estão numeradas e descritas a seguir: 
1. Para os biólogos, a memória está relacionada a reações adquiridas, inclusive imunológicas.

2. Em relação aos níveis de comportamento, chama-se comumente de memória a evocação de hábitos ou de reconhecimento, como quando uma poesia é lembrada. Neste caso acontece tanto uma conservação de esquema, porque houve aprendizagem, como um ato de evocação. Para os autores, conservar comportamentos constitui um "esquematismo" ou "conservação de esquemas", ou seja, refere-se à “(...) capacidade dos sujeitos de reproduzir o que é generalizável em um sistema de ações ou de operações" (Piaget \& Inhelder, 1979, p. 5). Ao "esquematismo" ou "conservação de esquemas" Piaget chamou de memória no sentido amplo. Esse é o tipo de memória que será objeto de estudo na presente pesquisa, cujo objetivo é caracterizar a memória considerando que, além da evocação absoluta de dados estáticos, é possível se apoiar em esquemas como recurso mnemônico.

3. Por último, os autores descrevem o que chamaram de memória no sentido estrito, que são as

(...) reações relativas a reconhecimentos (em presença do objeto) ou a evocações (em sua ausência), das quais o primeiro critério distintivo é uma referência explícita ao passado: o sujeito reconhece um objeto ou uma sequência de acontecimentos se ele tem a impressão de já tê-los visto antes (...) e a imagem-lembrança, na evocação mnêmica, se diferencia da imagem representativa em geral, (...) porque ela se faz acompanhar de uma localização no passado [...] e não apenas do conhecido em geral e ainda menos de previsto. (...) a memória no sentido estrito e a lembrança-imagem só se referem a situações, processos, objetos, que são singulares e reconhecidos e evocados como tais, em oposição aos esquemas, que são gerais (...) ou às imagens representativas que, embora sejam individuais, simbolizam um esquema geral (Piaget \& Inhelder, 1979, p. 6).

Assim, para eles, a conservação dos esquemas refere-se a um esquema que se atualiza por generalização, sem referência a um passado específico - por exemplo, um hábito pode existir sem nenhuma lembrança de sua formação. Há, assim, uma ligação entre o esquematismo e a memória de reconhecimento.
Piaget e Inhelder (1983) diferenciam dois tipos extremos de reconhecimento: um de caráter mnemônico, que é o fato de um bebê diferenciar sua mãe de um estranho, e um de caráter intuitivo, quando o bebê, ao ver pela primeira vez um novo móbile pendurado em seu berço, entende o movimento pelo simples fato de já ter feito isso com os móbiles antigos. Esse caso tem caráter esquemático, porque o bebê generalizou a função do móbile.

Piaget (1983), durante a conceituação de memória, ressalta que os teóricos de aprendizagem podem considerar que o desenvolvimento se dá por intermédio da aprendizagem, incluindo a dos esquemas. Entretanto, para o autor, é justamente o contrário, pois a aprendizagem não explica o desenvolvimento, uma vez que o que se aprende pode ser exógeno, e o desenvolvimento envolve, necessariamente, fatores de autorregulação e de equilíbrio. É essa organização que comanda a aprendizagem, e não o contrário. Por isso, não se trata aqui de diferenciar o que é um elemento representado por imagens ou símbolos de elementos motores. Os esquemas, por sua vez, apesar de serem transformados pela aprendizagem por meio do processo de acomodação, são mais oriundos dos processos de desenvolvimento. Por isso a conservação dos esquemas (desenvolvimento) é um problema bem diferente da memória em sentido estrito, e quanto mais elementar é o nível de desenvolvimento, mais atenuadas são a posição da memória em sentido estrito e a conservação dos esquemas.

A memória, para Piaget e Inhelder (1979),

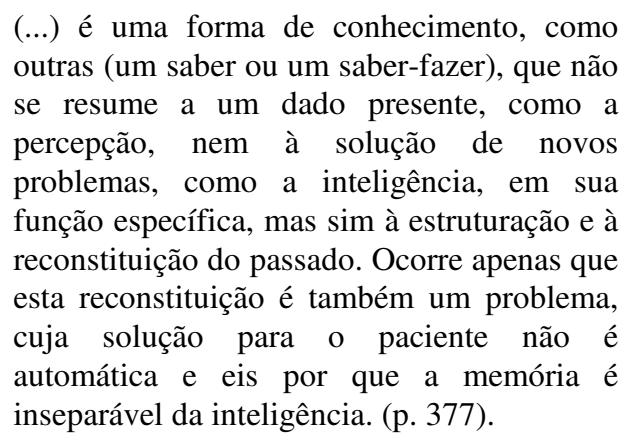

Os autores asseguram à memória um papel importante em relação à afetividade, pois colocam que sua função mais importante, do ponto de vista afetivo, é a de assegurar a identidade, de propiciar continuidade da vida mental. Cabe à memória conservar uma série de conhecimentos adquiridos, enquanto à inteligência cabe se ligar a novos problemas. Essas duas dimensões são, no caso do idoso, fundamentais para a manutenção de suas 
relações com os objetos (pessoas, adaptações cotidianas e consciência de si próprio).

Com o aumento da expectativa de vida, enfrentase, atualmente, o desafio de cuidar de um número maior de idosos que precisam manter-se ativos e independentes, e para isso a memória é uma função primordial. Uma questão que se coloca, então, é: como se dá o processo de memória em seu declínio, quando os aparatos orgânicos tendem a diminuir seu funcionamento? Situa-se o problema de pesquisa aqui colocado: trata-se de identificar não quanto a memória está preservada, mas quais são as relações estabelecidas entre a memória e a inteligência, esta última aqui entendida como a possibilidade de lançar mão ou de esquemas previamente construídos ou de construir novos esquemas.

Para haver ainda mais exatidão na formulação, o problema central aqui se refere a compreender como os esquemas construídos ao longo do desenvolvimento podem ajudar o idoso a manter-se autônomo, explicando, inclusive, o porquê de a escolaridade elevada diminuir a tendência ao declínio cognitivo. A hipótese de Piaget e Inhelder (1979) é que a conservação das lembranças se apoia sobre a conservação dos esquemas de hábito ou de inteligência, daí a estreita relação entre memória e inteligência. Assim, o objetivo da presente pesquisa é identificar o papel dos esquemas em um experimento de memória no sentido amplo, com seis mulheres acima de 60 anos.

\section{MÉTODO}

Em coerência epistemológica entre o referencial teórico e o método utilizado, optou-se por utilizar o método clínico piagetiano. Segundo Piaget (1975), para utilizar o método clínico é preciso reunir duas qualidades: saber observar e ao mesmo tempo saber buscar algo de preciso.

A caracterização do método clínico proposta pelo autor parece alertar para os cuidados necessários na realização da coleta de dados. Como se vê, a relação entre o problema de pesquisa aqui colocado e as proposições teóricas e metodológicas do autor fornece uma coerência interna ao delineamento da presente investigação.

\section{Local de pesquisa}

As participantes dessa pesquisa foram recrutadas em um grupo de terceira idade. Elas já se conheciam havia três anos e o experimento de memória foi realizado juntamente com outras atividades realizadas entre a pesquisadora e essas mulheres.

\section{Participantes}

A presente pesquisa se desenvolveu com a participação de seis mulheres acima de 60 anos. Uma condição básica para a participação da pesquisa foi a assinatura do Termo de Consentimento Livre e Esclarecido, que teve o propósito de esclarecer os detalhes dos procedimentos e comprovar a livre vontade das participantes. $\mathrm{O}$ modelo foi baseado nas normas referentes à realização de pesquisas envolvendo seres humanos, estabelecidas pela Resolução n. ${ }^{\circ}$ 196/96, de 10 de outubro de 1996, do Conselho Nacional de Saúde e na Resolução n. ${ }^{\circ}$ 016/2000, de 20 de dezembro de 2002, do Conselho Federal de Psicologia. O projeto foi aprovado pelo Comitê de Ética em Pesquisa da Universidade Federal do Espírito Santo. Os nomes utilizados ao longo da pesquisa são fictícios.

\section{Instrumento e procedimento}

$\mathrm{O}$ procedimento e o instrumento utilizados foram adaptados de um dos experimentos realizados por Piaget e Inhelder (1979). Assim, foram utilizados dois tabuleiros de madeira. O primeiro era o modelo a ser copiado, o qual mantém o formato do experimento adaptado de Piaget e Inhelder (1979), com a utilização do seguinte material: (1) dois tabuleiros de 28 × 28 cm, com 16 casas desenhadas; (2) 16 peças, todas com características diversas de tamanho e cor. As cores utilizadas no primeiro tabuleiro foram: vermelhoescuro, rosa-médio, rosa-claro e branco. Os tamanhos também foram, em ordem crescente: quadrados de 2,5 $\mathrm{cm}$, de $3,5 \mathrm{~cm}$, de $4,5 \mathrm{~cm}$ e de $5,5 \mathrm{~cm}$.

Um segundo tabuleiro utilizado foi do mesmo tamanho e com as mesmas peças que o primeiro; porém neste segundo tabuleiro havia oito peças de cor roxa, com três dos tamanhos utilizados no primeiro tabuleiro.

O tabuleiro é apresentado vazio, com as peças ao lado. Nessa etapa do experimento são acrescentados os distratores, que são peças dos mesmos tamanhos do modelo, mas com uma cor diferenciada (roxa).

Estes são os procedimentos para o experimento de memória: (1) mostra-se a cada participante, individualmente, o modelo, composto com 16 peças; (2) pede-se que o participante descreva o modelo, estimulando-o a verbalizar as características que observa, mas sem influenciá-lo: "Descreva para mim o que observa nesse tabuleiro"; "Alguma outra característica?"; (3) fecha-se a tampa do primeiro tabuleiro de modo a esconder o modelo; (4) entrega-se 
ao participante um tabuleiro vazio e espalham-se as 24 peças na mesa, incluindo as que têm a cor extra; (4) pede-se que seja reconstituído exatamente o modelo; (5) caso o participante não reconstitua corretamente a seriação das peças, mostra-se o tabuleiro inicial e pede-se que ele analise o que aconteceu, sem maiores interferências. Após essas considerações, fecha-se o tabuleiro original e pede-se novamente a reconstituição. Caso não consiga novamente acertar o modelo, não há outra tentativa.

Cada uma das distribuições no tabuleiro é fotografada, de modo a registrar a configuração criada por cada participante e seus comentários são gravados em áudio.

\section{Critérios de análise}

Os critérios de análise foram adaptados de Piaget e Inhelder (1979) e avaliados por um juiz com formação em psicologia, doutorando do Programa de Pós-Graduação em Psicologia da Universidade Federal do Espírito Santo. Todas as avaliações coincidiram, ou seja, os mesmos níveis atribuídos durante a pesquisa também o foram pelo juiz, indicando clareza e objetividade na descrição de cada nível.

Nível I: começa-se a reconstituir o modelo de forma aleatória, sem demonstrar nenhum critério. Mencionam-se as cores ou tamanhos, mas não se relata relação entre eles, além de usar, também, o elemento distrator (cor extra). A maneira de colocar as peças no tabuleiro não contempla nenhuma organização, nem por cor nem por tamanho, de forma a não estabelecer nenhuma sequência entre essas peças.

Nível II: consegue-se demonstrar lembrança de algum detalhe do modelo anterior, seja pela escolha das cores, seja pelo tamanho das peças; porém ainda não se respeitam os esquemas necessários para colocálas em sequência, seja de cor, seja de tamanho. Ao descrever o tabuleiro, inicialmente, pode-se até mencionar uma seriação, mas tal fato não se repete quando se precisa, sem ajuda, repetir as sequências propostas no modelo. Podem acontecer situações como: (1) colocar fileiras com mesma cor, mas não sequenciar as fileiras da mais clara para a mais escura; (2) colocar fileiras da mesma cor com tamanhos em ordem crescente em algumas peças e em outras, não; (3) respeitar um dos atributos (cor ou tamanho), mas sem coordenar os dois.

Nível III: demonstra-se capacidade de realizar uma seriação, com esquema antecipador, mas levandose em consideração apenas um dos critérios - ou tamanho, ou cor. Em geral, fica claro que o indivíduo possui o esquema, mas se deixa confundir pelo elemento distrator. Apesar disso, ele demonstra dificuldade em evocar os dados, ou seja, demonstra dificuldade com a memória de sentido estrito. Podem acontecer situações como: (1) respeitar a sequência de cores, mas não de tamanho; (2) respeitar a sequência de tamanho, mas não de cores. Tais situações também podem acontecer em outros níveis, mas, apesar de o raciocínio e as justificativas estarem corretas, ainda ocorrem erros, embora pequenos. Por exemplo, o tabuleiro é montado com a sequência correta de tamanhos e em tons gradativamente mais escuros, mas do rosa médio para o roxo, excluindo o branco. Nesse caso, costuma haver desequilíbrio e o participante demonstra que considera que algo está errado, mas não sabe ainda o quê.

Nível IV/A: o método de montagem do tabuleiro é de dupla seriação imediatamente antecipadora, depois da percepção do modelo. Como dito anteriormente, trata-se de uma memória muito mais elaborada, que compreende uma transformação do objeto e do sujeito. Ao comparar com o modelo na segunda tentativa, percebe-se o erro e em geral a pessoa consegue acertar. É um erro relacionado mais à falta de atenção do que aos esquemas de seriação e classificação.

Nível IV/B: mantêm-se as características no nível A, mas o tabuleiro fica idêntico ao modelo já na primeira tentativa. O que caracteriza o nível IV/B é que o elemento distrator não causa perturbação, porque é imediatamente percebido.

\section{RESULTADOS E DISCUSSÃO}

Os níveis de memória apresentados pelas participantes foram:

(1) Cláudia (67 anos, casada, Ensino Superior) nível IV/B;

(2) Doralice (62 anos, casada, Ensino Médio) - nível IV/A;

(3) Êda (63 anos, divorciada, Ensino Médio) - nível IV/B;

(4) Iranilce (65 anos, casada, Ensino Médio; apresentou queixa de problema com a memória) nível III;

(5) Janaína (65 anos, viúva, Ensino Médio) - nível $\mathrm{IV} / \mathrm{B}$;

(6) Neuma (61 anos, casada, Ensino Médio, queixa-se de problema de memória) - nível IV/B.

A convivência com as participantes dessa pesquisa ocorreu ao longo de um semestre, o que 
permitiu conhecer suas características e suas habilidades. Apenas duas delas apresentaram queixas de problemas de memória - Iranilce e Neuma. Como se pôde observar, apenas a primeira apresentou, de fato, um nível inferior em relação às demais participantes. Este dado está de acordo com a literatura científica, uma vez que estudos comprovaram não haver relação direta entre queixa de memória e desempenho cognitivo (Mendes, Ginó, Ribeiro, Guerreiro, Souza, Ritchie, \& Mendonça, 2008; Paulo \& Yassuda, 2010; Weaver, Collie, Masters, \& Maruff, 2007).

Associação direta foi encontrada em relação à ansiedade e a queixas de memória, indicando que a queixa de memória é um fato a ser considerado no acompanhamento do idoso, mas não necessariamente está relacionado a problemas de memória (Potter, Hartman, \& Ward, 2009).

Segundo Parente (2006), além de as queixas subjetivas de memória não estarem correlacionadas aos resultados nos testes formais de memória, é preciso considerar também que a atenção é outro processo básico que pode ser afetado no envelhecimento, causando prejuízo no resultado final da memorização. Este foi um aspecto que desde o início acompanhou a definição do objetivo da presente pesquisa - identificar o papel dos esquemas na memória. A decisão metodológica foi manter-se no viés epistemológico adotado, principalmente, porque não era objeto de estudo o resultado das participantes, mas sim, o entendimento de como a memória poderia ou não se apoiar nos esquemas previamente construídos, tal como sugerido por Piaget e Inhelder (1979).

Para exemplificar o desempenho da Sra. Iranilce, segue relato do experimento. Ela precisou das duas tentativas, e ainda assim não conseguiu montar adequadamente o tabuleiro. Ela estava preocupada com o horário, uma vez que ficou aproximadamente 40 minutos conversando sobre questões pessoais que a estavam incomodando. Quando estava fazendo o experimento, chegou outra participante que estava marcada, e ela pareceu incomodada. Apesar de, possivelmente, tal fato ter atrapalhado seu desempenho, nas outras atividades realizadas ao longo de um semestre em que houve contato, ela também demonstrou comportamento diferenciado das outras participantes, mostrando-se distraída e errando mais que a maioria nas atividades que desenvolvia.

Pesquisadora: "Queria que você olhasse e descrevesse para mim o que você está vendo no tabuleiro."
Iranilce: "Maior, menor, médio (indício de seriação)."

Pesquisadora: "Que mais?”

Iranilce: "cores, é... rosa-salmão, rosa-bebê, rosa-claro, branco."

Pesquisadora: "Agora eu vou mostrar esse tabuleiro e você pode usar qualquer dessas peças e tentar montar igual ao primeiro."

Iranilce: "E se eu me perder?"

Pesquisadora: "Não tem problema nenhum se você se perder."

Iranilce: “[estou] fazendo rápido para não atrasar a colega."

Pesquisadora: "Aí também não adianta. Faz do seu jeito."

Iranilce: "Do meu jeito? Eu pensei que era para fazer igual."

Pesquisadora: "Igual, mas no seu tempo."

Iranilce: "Ah, meu pai..."

(o tabuleiro montado por ela foi fotografado e o modelo foi apresentado para comparação).

Pesquisadora: "Agora eu vou te mostrar esse aqui e você vai me dizer se está igual."

Iranilce: "O meu ficou faltando... porque não tinha a cor..."

Pesquisadora: "Está igual?"

Iranilce: "As cores, não, mas a posição está."

\section{Tabuleiro de memória de Iranilce: $\mathbf{1}^{\mathrm{a}}$ tentativa}

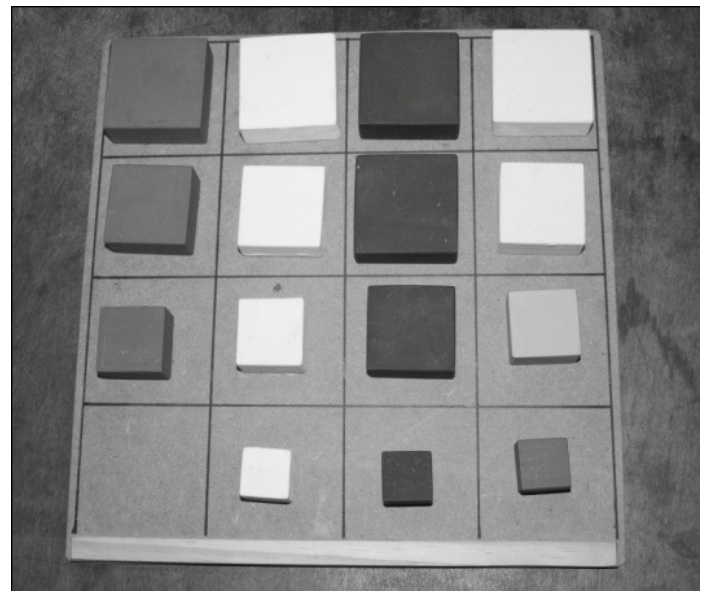

Ela não atentou para as cores, a ponto de deixar o quadrado menor em uma fileira de outra cor (como se vê na fileira da direita), além de não se perturbar com 
o fato de ficar vazia uma casa do tabuleiro. Os quadrados mais escuros, por sua vez, também ficaram com dois tamanhos iguais, e não decrescentes, como no modelo.

Pesquisadora: "Então tenta fazer igual, em tudo."

Iranilce: "Em tudo?"

Pesquisadora: "É."

Iranilce: "Eu olhando para aí (para o modelo)

Pesquisadora: Não. (risos)"

Iranilce: "Ah, malvada.(risos)"

(conversou e montou ao mesmo tempo)

Iranilce: "Gente... o que está faltando aqui, pai. Acho que é essa. Eu acho. E ficou certo?"

Ao montar o tabuleiro pela segunda vez, ela não respeitou as cores, colocando as peças brancas entre as peças rosa-claro e rosa-escuro. Observou-se, assim, que ela não conseguiu reter a informação nem sobre as cores utilizadas nem sobre a seriação de cores, mas conseguiu perceber a seriação dos tamanhos, fazendo com que o tabuleiro respeitasse a ordem de alguns tamanhos que estavam no modelo, exceto pelos quadrados grandes mais escuros, que propositalmente não possuíam o segundo tamanho, e ela colocou dois iguais.

Ela perguntou: "Ficou certo?" esperando uma afirmativa externa, sendo que ela mesma não mencionou as incoerências no tabuleiro. Os esquemas de seriação construídos ao longo de sua vida provavelmente sustentam uma atividade cognitiva que dá conta de seu cotidiano, já que ela tem um estilo de vida autônomo - paga suas contas, cuida da casa e dos netos, participa de vários grupos de terceira idade. Se ela tivesse que contar apenas com os recursos de atenção e memória que lhe cabem no momento, é possível que tivesse mais prejuízos. Pesquisas sistematizadas com intervenções e estudo de caso longitudinal poderão responder às hipóteses sugeridas pelos dados, ou seja, que os esquemas de seriação suprem deficiências decorrentes do declínio cognitivo.

Os esquemas de seriação parecem, também no próximo caso, ter auxiliado a recuperação dos dados do tabuleiro no experimento da Sra. Doralice. Como se poderá observar, ela consegue montar um tabuleiro igual ao modelo apenas na segunda tentativa, porque da primeira vez ela não se deu conta do atributo cor, apenas do tamanho. Ainda assim, mesmo na primeira vez respeitou o esquema de seriação, ficando perturbada porque percebeu que havia uma cor sobrando.

Pesquisadora: "Descreve para mim o que você está vendo no tabuleiro?"

Doralice: "É um jogo como escadinha. A pedra branca, a pedra rosa, rosa clara, rosa médio, rosa forte, da pequena para a maior. A primeira fileira pequena, a segunda, médio e grande. (ela já observa a seriação)"

Pesquisadora: "eu vou agora te pedir a gentileza de montar um tabuleiro igual àquele."

Doralice: “Ah, tá. Cada pedrinha fica cada uma em um quadrado, ou... (ela não se lembrou da localização de cada peça, ou seja, falhou a memória no sentido estrito, de recuperação imediata da informação. Se o experimento se preocupasse apenas com o resultado, o restante do processo não seria analisado)"

Pesquisadora: "pode ser. “

Doralice: "Uma aqui, uma aqui, uma aqui e outra aqui, não é? (apontou para cada quadrado, perguntado sobre a regra do experimento)."

Pesquisadora: "Isso."

Doralice: "Uai, sobra pedrinha?"

Pesquisadora: "Onde?"

(continua montando. Depois, foi fotografada)

Tabuleiro de memória de Doralice: $\mathbf{1}^{\mathrm{a}}$ tentativa

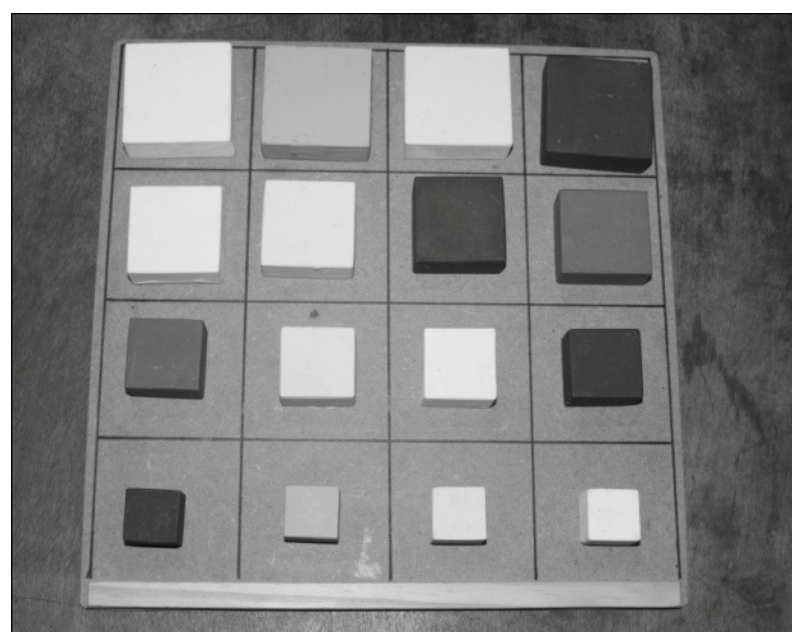

Ela monta o tabuleiro respeitando a seriação de tamanho, não de cor. Faz isso, mas se sente perturbada por sobrarem peças. 
Pesquisadora: “Agora, eu vou te mostrar o tabuleiro original e você vai me dizer se está parecido com esse."

Doralice: "Hum. Você colocou outra cor. Todas as fileiras são brancas. A fileira é branca, outra rosa, outra rosa..."

Pesquisadora: "Agora, eu vou fechar e você tenta fazer outro igual. Combinado?"

Doralice acena afirmativamente com a cabeça e começa a montar novamente o tabuleiro.

Doralice: "Essa cor é forte. Não tem lugar para colocar."

Pesquisadora: "É?"

Doralice: "silêncio."

Pesquisadora: "É ou não é?"

Doralice: "É, porque essa aqui (pedra roxa) não tem lugar para colocar."

Pesquisadora: "Essa aqui, qual?"

Doralice: "Essa roxona, forte."

(da segunda vez, acertou)

Ela demonstra apoiar-se no esquema de seriação quando menciona: "é um jogo como escadinha", mas não se lembra de que cada quadrado fica em um espaço específico no tabuleiro. A cor extra (roxa) a distrai, mas ela sabe que não haviam sobrado peças no modelo e fica um tempo para tomar a decisão do que fazer com a peça extra. Como sua memória no sentido estrito estava falha, ela se apoiou nos esquemas de seriação para montar o tabuleiro, e, ao ver o modelo pela segunda vez, entende seu erro e monta o tabuleiro corretamente.

O papel do erro, inclusive, é importante no paradigma construtivista. Para Macedo (1994), a revisão constante dos erros tem papel importante no desenvolvimento. Ao entender o erro, o sujeito pode construir novos esquemas, coordenando ações de formas diferenciadas.

Uma participante que alcançou o nível IV/B, a Sra. Êda, também se apoia em esquemas de seriação, como se observa no diálogo que se segue.

Pesquisadora: "Êda, o que você está vendo? Descreva pra mim. “

Êda: "Você vê numa ordem que vem diminuindo não é? Vem do maior para o menor, ou do menor para o maior. As cores."

Pesquisadora: "Quais são as cores?"
Êda: "Esse aqui é o rosa choque, esse é o goiaba, esse é o bebê, esse é o branco."

Pesquisadora: "Agora eu vou lhe pedir que, com essas peças aqui, você reproduza no tabuleiro aquela montagem, o mais semelhante que você puder."

Êda: "Do mesmo jeito?"

Pesquisadora: "Do mesmo jeito."

(silêncio)

Pesquisadora: "Vai me dizendo o que você está pensando."

Êda: "O branco, o bebê, o goiaba e o rosachoque."

(acertou o modelo)

Pesquisadora: "Por que você não usou essas cores aqui? “

Êda: Porque... primeiro porque eu não gosto de vermelho, apesar de que isso aqui é um vinho. Só que também ali não tinha o vinho, tinha o rosa-choque.

Além de se apoiar na memória estrita, ela também usa o esquema de seriação. Assim, parece que para atingir um nível alto de recuperação de informação nesse experimento é necessário usar tanto o esquematismo quanto a memória de sentido estrito. As demais participantes que atingiram esse nível demonstraram o mesmo raciocínio e usaram os dois tipos de memória; entretanto, as que falharam em relação à memória no sentido estrito só conseguiram avançar quando se apoiaram no esquematismo.

\section{CONSIDERAÇÕES FINAIS}

As intervenções com idosos saudáveis tornam-se cada vez mais um desafio para a Psicologia. De acordo com a revisão de literatura realizada, há uma tendência a estudar procedimentos para se medirem com precisão os resultados da memória, o que é fundamental quando se trata de diagnóstico e de diferenciar queixas subjetivas de memória dos problemas ocasionados por demência ou outros acometimentos orgânicos; entretanto, também é necessário desenvolver estratégias para intervir nos declínios cognitivos e/ou preveni-los, tanto em idosos saudáveis quanto em idosos que já apresentem algum prejuízo cognitivo.

De acordo com Ribeiro, Neri, Cupertino e Yassuda (2009), é preciso avançar nas investigações sobre o conceito de envelhecimento ativo e suas 
implicações no bem-estar físico e psicológico dessa população, melhorando os estudos epidemiológicos. $\mathrm{Na}$ perspectiva piagetiana, o desenvolvimento não tem um fim determinado cronologicamente, e o estilo de vida pode contribuir para a construção de novos procedimentos, além de manter aqueles já construídos.

$\mathrm{O}$ paradigma piagetiano de valorizar positivamente o erro e trabalhar compreendendo a construção e a utilização de esquemas na resolução de problemas parece ser um caminho viável para futuras pesquisas, pois ajudar o sujeito a compreender sua forma de pensar, apoiando-se em esquemas já construídos para dar conta do cotidiano. Além de valorizar o erro, também se prioriza o que ainda está preservado em termos de esquemas e de funções cognitivas, melhorando a autoestima e apontando caminhos para a intervenção.

\section{REFERÊNCIAS}

Macedo, L. (1994). Ensaios construtivistas. São Paulo: Casa do Psicólogo.

Mendes, T., Ginó, S., Ribeiro, F., Guerreiro, M., Souza, G., Ritchie, K., \& Mendonça A. (2008). Memory complaints in healthy young and elderly adults: Reliability of memory reporting. Aging \& Mental Health, 12(2). Recuperado em 30 de abril, 2011, de http://www.informaworld.com/smpp/content $\sim \mathrm{db}=$ all $\sim \mathrm{co}$ ntent $=\mathrm{a} 791904145 \sim \mathrm{frm}=\mathrm{abslink}$ ? words=memory,compl aints.

Parente, M. A. M. P. (2006). Cognição e envelhecimento. Porto Alegre: Artmed.

Paulo, D. L. V., \& Yassuda, M. S. (2010). Queixas de memória de idosos e sua relação com escolaridade, desempenho cognitivo e sintomas de depressão e ansiedade. Revista de psiquiatria clínica, 37(1). Recuperado em 30 de abril, 2011, de http://www.scielo.br/pdf/rpc/v37n1/a05v37n1.pdf.

Piaget J. (1975). Os problemas e os métodos. In: $A$ representação do mundo na criança. Rio de Janeiro: Record.

Piaget J., \& Inhelder B. (1979). Memória e inteligência. São Paulo: Artenova.
Piaget, J. (1983). Problemas de psicologia genética. Lisboa: Dom Quixote.

Potter, G. G., Hartman, M., \& Ward, T. (2009). Perceived stress and everyday memory complaints among older adult women. Anxiety, Stress \& Coping: An International Journal, 22(4). Recuperado em 30 de abril, 2011, de http://www.informaworld.com/smpp/content $\sim \mathrm{db}=$ all $\sim \mathrm{co}$ ntent=a910059093 frm=abslink ?words=memory,compl aints.

Resolução 016/2000. (2000). Dispõe sobre a realização de pesquisa em Psicologia com seres humanos. Brasília, DF: Ministério da Saúde. Recuperado em 5 de maio, 2007, de http://www.bioetica.ufrgs.br/res16cfp.htm.

Resolução 196/96. (1996). Dispõe sobre as diretrizes e normas regulamentadoras de pesquisa envolvendo seres humanos. Brasília, DF: Ministério da Saúde. Recuperado em maio, 2007, de http://www.fmb.unesp.br/etica_pesquisa/docs/resolucao _196.pdf.

Ribeiro, P. C. C., Neri, A. L., Cupertino, A. P. F. B., \& Yassuda, M. S. (2009). Variabilidade no envelhecimento ativo segundo gênero, idade e saúde. Psicologia e Estudo, 14(3). Recuperado em 30 de abril, 2011,

de http://www.scielo.br/scielo.php?script=sci_arttext\&pid= S1413-73722009000300011.

Weaver, J. C., Collie A., Masters C., \& Maruff, P. (2007). The nature of cognitive complaints in healthy older adults with and without objective memory decline. Journal of Clinical and Experimental Neuropsychology, 30(2) Recuperado em 30 de abril, 2011, de http://www.informaworld.com/smpp/content $\mathrm{db}=\mathrm{all} \sim$ content $=\mathrm{a} 789796135 \sim \mathrm{frm}=$ abslink? words=memory, complaints. 